Check for updates

Cite this: RSC Adv., 2019, 9, 23622

Received 15th June 2019 Accepted 22nd July 2019

DOI: $10.1039 / c 9 r a 04495 g$

rsc.li/rsc-advances

\section{The enzyme-like catalytic hydrogen abstraction reaction mechanisms of cyclic hydrocarbons with magnesium-diluted Fe-MOF-74†}

\author{
Wen-zhi Luo, (1D a Guang-hui Chen, (D) *a Song-tao Xiao, ${ }^{\text {*b }}$ Qiang Wang, (D) ${ }^{c}$ \\ Ze-kun Huang ${ }^{d}$ and Ling-yu Wang ${ }^{b}$
}

Enzymatic heme and non-heme Fe(IV)-O species usually play an important role in hydrogen abstraction of biocatalytic reactions, yet duplicating the reactivity in biomimicry remains a great challenge. Based on Xiao et al.'s experimental work [Nat. Chem., 2014, 6(7), 590], we theoretically found that in the presence of the oxidant $\mathrm{N}_{2} \mathrm{O}$, the enzyme-like metal organic framework, i.e., magnesium-diluted Fe-MOF-74 [Fe/(Mg)MOF-74] can activate the $\mathrm{C}-\mathrm{H}$ bonds of 1,4-cyclohexadiene (CHD) into benzene with a two-step hydrogen abstraction mechanism based on the density functional theory (DFT) level. It is shown that the first transition state about the cleavage of the $\mathrm{N}-\mathrm{O}$ bond of $\mathrm{N}_{2} \mathrm{O}$ to form the Fe(IV)-O species is the rate-determining step with activation enthalpy of $19.4 \mathrm{kcal} \mathrm{mol}^{-1}$ and the complete reaction is exothermic by $62.8 \mathrm{kcal} \mathrm{mol}^{-1}$ on quintet rather than on triplet PES. In addition, we proposed a rebound mechanism of cyclic cyclohexane ( $\mathrm{CHA})$ hydroxylation to cyclohexanol which has not been studied experimentally. Note that the activation enthalpies on the first hydrogen abstraction for both cyclic $\mathrm{CHD}$ and cyclohexane are just 8.1 and $3.5 \mathrm{kcal} \mathrm{mol}^{-1}$, respectively, which are less than that of $13.9 \mathrm{kcal} \mathrm{mol}^{-1}$ for chained ethane. Most importantly, for the hydrogen abstraction of methane catalyzed by $\mathrm{M} /(\mathrm{Mg})$ MOF-74 ( $\mathrm{M}=\mathrm{Cu}, \mathrm{Ni}, \mathrm{Fe}$, and $\mathrm{Co}$ ), we found that the activation enthalpies versus the $\mathrm{C}-\mathrm{H}$ bond length of methane of TSs, NPA charge of the reacting oxyl atom have linear relationships with different slopes, i.e., shorter $\mathrm{C}-\mathrm{H}$ bond and less absolute value of NPA charge of oxyl atom are associated with lower activation enthalpy; while for the activation of methane, ethane, propane and CHD catalyzed by Fe/(Mg)MOF-74, there also exists positive correlations between activation enthalpies, bond dissociation energies (BDEs) and $\mathrm{C}-\mathrm{H}$ bond lengths in TSs, respectively. We hope the present theoretical study may provide the guideline to predict the performance of MOFs in $\mathrm{C}-\mathrm{H}$ bond activation reactions.

\section{Introduction}

Converting the relatively inactive $\mathrm{C}-\mathrm{H}$ bond of hydrocarbons into higher value commodity chemicals, i.e., alcohol, aldehyde, and carboxylic acid remains a great challenge with enormous economic and environmental effect., ${ }^{\mathbf{1} 2}$ Metalloenzymes have attracted great attention due to their special structures and functions as a target mimicking model. ${ }^{3-5}$ It is the high valent $\mathrm{Fe}(\mathrm{Iv})-\mathrm{O}$ of heme and nonheme enzymes that play crucial roles in selectively functionalizing $\mathrm{C}-\mathrm{H}$ bonds. ${ }^{6-11}$ There are two

${ }^{a}$ Department of Chemistry, Shantou University, Guangdong 515063, China. E-mail: ghchen@stu.edu.cn

${ }^{b}$ Institute of Radiochemistry, China Institute of Atomic Energy (CIAE), Beijing, 102413, People's Republic of China. E-mail: xiao200112@163.com

'Department of Applied Chemistry, College of Science, Nanjing Tech University, Nanjing 211816, People's Republic of China. E-mail:wangqiang@njtech.edu.cn

${ }^{d}$ The Wolfson Department of Chemical Engineering, Israel Institute of Technology, Israel.E-mail: zekun-h@campus.technion.ac.il

$\dagger$ Electronic supplementary information (ESI) available. See DOI: 10.1039/c9ra04495g methods to achieve the $\mathrm{Fe}(\mathrm{Iv})-\mathrm{O}$ high spin species: the first approach corresponds to utilizing weak-field ligands in an octahedral structure. Take $\left[\mathrm{Fe}(\mathrm{Iv}) \mathrm{O}\left(\mathrm{H}_{2} \mathrm{O}\right)_{5}\right]^{2+}$ as an example, ${ }^{\mathbf{1 1}}$ it has an quintet ground state and the substitution of water molecules by the strong-field ligands will lead to the triplet state; ${ }^{12}$ the other method corresponds to making use of trigonal bipyramidal geometry. For instance, the $\left[\mathrm{Fe}(\mathrm{Iv}) \mathrm{O}-\left(\mathrm{TMG}_{3} \text { tren }\right)\right]^{2+}$ ( $\mathrm{TMG}_{3}$ tren $=1,1,1$-trisamine) has a quintet ground state with trigonal bipyramidal structure, as characterized by Mössbauer spectroscopy. ${ }^{13}$

Metal organic frameworks (MOFs) are important porous crystalline materials that are composed of inorganic metal sites and organic ligands, which has been another vital structure that can be used for heterogeneous catalysis with $\mathrm{Fe}$ or other metals. ${ }^{14-19}$ The inner pores of these MOFs can determine reaction selectivity, and significantly, the structure of the pores can be changed by adjusting the organic ligands and metal sites. Like heme and nonheme enzymes of $\mathrm{Fe}(\mathrm{Iv})-\mathrm{O}$ intermediate, another attractive feature of MOFs is that redox active metals can be utilized as activity center, which can perform 
behavior similar to that in metalloenzymes, possibly exhibiting powerful enzyme-like catalytic activity. The MOF with isolated terminal $\mathrm{Fe}(\mathrm{Iv})-\mathrm{O}$ is a highly promising area of research. In addition, although the $\mathrm{Fe}(\mathrm{Iv})-\mathrm{O}$ intermediates generally make use of nitrogen-based chelating ligands, the metal center in MOF is also often linked by weak-field ligands, such as aryl oxides and carboxylates, which are surrounded in the coordination environment of framework structure. Thus, these materials may also have special electronic properties and reactivity imparted by their unique coordination environment. Indeed, $\mathrm{C}-\mathrm{H}$ bond activation of chained hydrocarbons by MOFs have received extensive attentions. For example, Dale R. Pahls et $a .^{20}$ reported $\mathrm{Cu}$-functionalized NU-1000 MOF material can catalyze methane to methanol; Sarawoot Impeng et al. ${ }^{21}$ found that the $\mathrm{C}-\mathrm{H}$ bond activation of ethane on the $\mathrm{Fe}(\mathrm{Iv})-\mathrm{O}$ species in a Zn-based cluster of MOFs; Xiao et al. ${ }^{22}$ have experimentally reported that a high-spin $\mathrm{Fe}(\mathrm{Iv})-\mathrm{O}$ species can be formed in magnesium-diluted Fe-MOF-74 [Fe/(Mg)-MOF-74] and thus affects the hydroxylation of ethane [Nat. Chem., 2014, 6(7), 590]. The weak-field ligand in magnesium-diluted Fe-MOF-74 obviously provide a suitable environment for a high-spin $\mathrm{Fe}(\mathrm{Iv})-\mathrm{O}$ to induce hydrogen abstraction reaction. Note that Xiao et al. ${ }^{23}$ have also found that expanded Fe-MOF-74 analogues can experimentally catalyze the reaction of cyclohexane to cyclohexanol but there exists also byproduct cyclohexanone, however, the $\mathrm{Mg}$ diluted $\mathrm{Fe} /(\mathrm{Mg})-\mathrm{MOF}-74$ in which 5\% of the $\mathrm{Mg}$ atoms are substituted by Fe can hydroxylate ethane to ethanol to avoid overoxidation. ${ }^{22}$ And using nitrous oxide as an oxidant, Fe/ (Mg)-MOF-74 can catalyze 1,4-cyclohexadiene (CHD) oxidation to produce benzene. ${ }^{22}$ However, no mechanism has been reported so far about the present reaction of catalysis oxidation of such a type of cyclic hydrocarbon, i.e., CHD. Surely, without carrying out accurate quantum chemistry calculations, we cannot understand the reaction mechanism in detail.

Therefore, we decide to study above reaction mechanism of CHD conversion to benzene catalyzed by Fe/(Mg)-MOF-74 with $\mathrm{N}_{2} \mathrm{O}$ as oxidant using Kohn-Sham density functional theory (DFT). ${ }^{24}$ Here we firstly propose the mechanism for oxidation of cyclic CHD, which corresponds to two-step hydrogen abstraction reactions with the primary products being benzene. In addition, we also proposed a rebound mechanism of cyclohexane (CHA) hydroxylation to cyclohexanol using $\mathrm{Fe}(\mathrm{Iv})-\mathrm{O}$ species of $\mathrm{Fe} /(\mathrm{Mg})-\mathrm{MOF}-74$ which has not been studied experimentally. Most importantly, we have built up the linear relationship between the activation enthalpies and descriptors, such as, the NPA charge of oxyl atoms, C-H lengths in TSs, and bond dissociation energy (BDE) of $\mathrm{C}-\mathrm{H}$ bonds for different hydrocarbons with a series of $\mathrm{M} /(\mathrm{Mg})-\mathrm{MOF}-74(\mathrm{M}=\mathrm{Cu}, \mathrm{Ni}, \mathrm{Fe}$, and Co), respectively, using the density functional theory (DFT).

\section{Computational methods}

Because the hydrogen abstraction reaction was observed with the catalysis of $\mathrm{Fe} /(\mathrm{Mg})$-MOF-74 where Fe is diluted by $\mathrm{Mg},{ }^{22}$ we can make a hypothesis that the reaction occurs at a single Fe site and does not require the interactions of Fe-Fe. ${ }^{25}$ Therefore, we build a model of $\mathrm{Fe} /(\mathrm{Mg})$-MOF-74 by carving a cluster from the crystal structure where the central metal site is Fe and the other two metal sites are Mg, as shown in Fig. 1(a). The dangling bonds of the cluster were saturated by hydrogen atoms to make the cluster neutral. The optimized cluster with one Fe atom, two $\mathrm{Mg}$ atoms and six organic ligands is shown in Fig. 1(b). For the sake of clarity, we chose the six atoms model to represent Fe/ (Mg)-MOF-74, as shown in Fig. 1(c).

DFT approaches including dispersion-corrected (DFTD) ${ }^{26-28}$ is implemented to treat structures with long range dispersion interactions and give good results for geometry and energy of MOF. ${ }^{29-32}$ All Kohn-Sham calculations were performed with the M06- $\mathrm{L}^{33}$ exchange-correlation functional including D3 dispersion-corrected, ${ }^{27}$ which performs well for long range electron correlation effects and transition metal chemistry. $^{22,34-36}$ Since the B3LYP-D3 has also been used to study the $\mathrm{Fe}-\mathrm{O}$ chemistry recently, ${ }^{37}$ we did test calculations to see how it performs compared with M06-L-D3 exchangecorrelation functional as shown in Table $\mathrm{S} 1 . \dagger$ From comparison with the bond lengths of the experimental structure and calculated ones, M06-L-D3 exchange-correlation functional performed better, i.e., the calculated relative error remains at about $0.25 \%$ compared with the experimental results. To reduce computational cost, we used the following strategy: geometry optimizations were adopted with the LANL2TZ(f) ${ }^{\mathbf{3 8 - 4 0}}$ basis set for the valence electrons of Fe atom and the $6-31 G(d, p){ }^{41}$ basis set for the other atoms, while effective core potential (LANL2) was employed for Fe. To get the reliable relative energy, the single-point energies were refined at the optimized geometries with same exchange-correlation functional and a def2-TZVP ${ }^{42}$ basis set for all atoms. Note that the $\mathrm{Fe} /(\mathrm{Mg})$-MOF-74 cluster initially carved from the crystal structures were fully optimized. All transition states (TSs) were identified with one imaginary frequency, and internal reaction coordinate (IRC) calculations were carried out to prove that the TSs connecting the right reactants and products. The DFT calculations were performed with Gaussian 16 program package. ${ }^{43}$ The natural population analysis (NPA) were carried out based on the natural bond orbital theory with NBO 3.1 module $^{\mathbf{4 4 , 4 5}}$ as incorporated in Gaussian 16 package, while electron localization function $(\mathrm{ELF})^{\mathbf{4 6}}$ calculations to determine bonding nature were performed with Multiwfn 3.6 package. ${ }^{47}$

\section{Results and discussion}

For concise, we organized the content as follows: in Section 3.1, we mainly discussed the catalytic cycle for the oxidation of 1,4cyclohexadiene (CHD) by $\mathrm{N}_{2} \mathrm{O}$ with the catalysis of $\mathrm{Fe} /(\mathrm{Mg})$ MOF-74; in Section 3.2, the electronic structure analysis was performed for the oxidation of CHD; in Section 3.3, we proposed a rebound mechanism of cyclohexane ( $\mathrm{CHA}$ ) hydroxylation to cyclohexanol catalyzed by $\mathrm{Fe}(\mathrm{Iv})-\mathrm{O}$ species; in Section 3.4, we further explored the linear relationships between the activation enthalpies and descriptors, such as, the NPA charge of oxyl atoms, $\mathrm{C}-\mathrm{H}$ lengths in TSs, and bond dissociation energy (BDE) of $\mathrm{C}-\mathrm{H}$ bonds for different hydrocarbons with the catalysts of $\mathrm{M}$ / (Mg)-MOF-74 (M = Cu, Ni, Fe, and Co). 


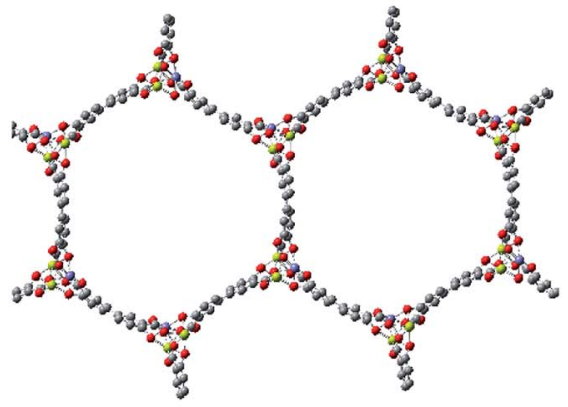

(a)

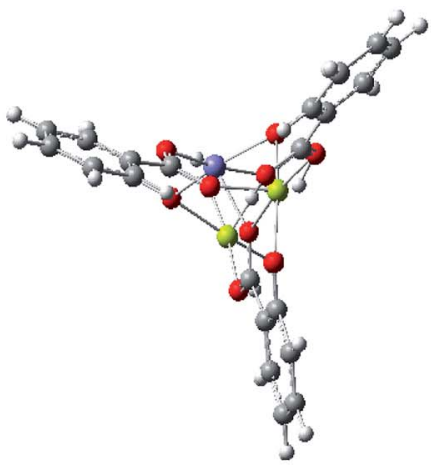

(b)

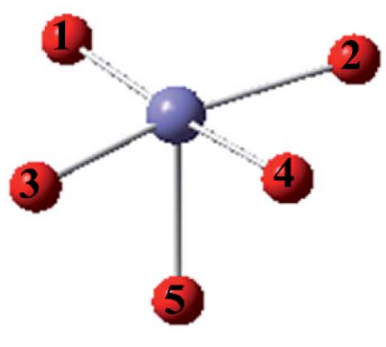

(c)

Fig. 1 The structure of (a) magnesium-diluted Fe-MOF-74; (b) cluster model; and (c) six atoms model (color code: purple = Fe, red = O, light green $=M g$, gray $=C$, and white $=H$ ).

\subsection{Catalytic cycle for the oxidation of 1,4-cyclohexadiene} (CHD)

In order to interpret the reaction mechanism of CHD oxidized by $\mathrm{N}_{2} \mathrm{O}$ with the catalysis of $\mathrm{Fe} /(\mathrm{Mg})-\mathrm{MOF}-74$ experimentally reported by Xiao et $a .^{22}$ we decide to carry out a theoretical calculation. At the DFT/M06-L-D3 level, it is found that the reaction proceeds with a catalytic cycle for the oxidation of CHD to benzene using enthalpy change as plotted in Scheme 1. The calculated $\Delta H$ and $\Delta G$ for various species are collected in Table S2. $\dagger$ It is shown that there are three key steps with three transition-state structures in the catalytic cycle corresponding to: (1) formation of a $\mathrm{Fe}(\mathrm{Iv})-\mathrm{O}$ intermediate with the $\mathrm{O}$ atom of

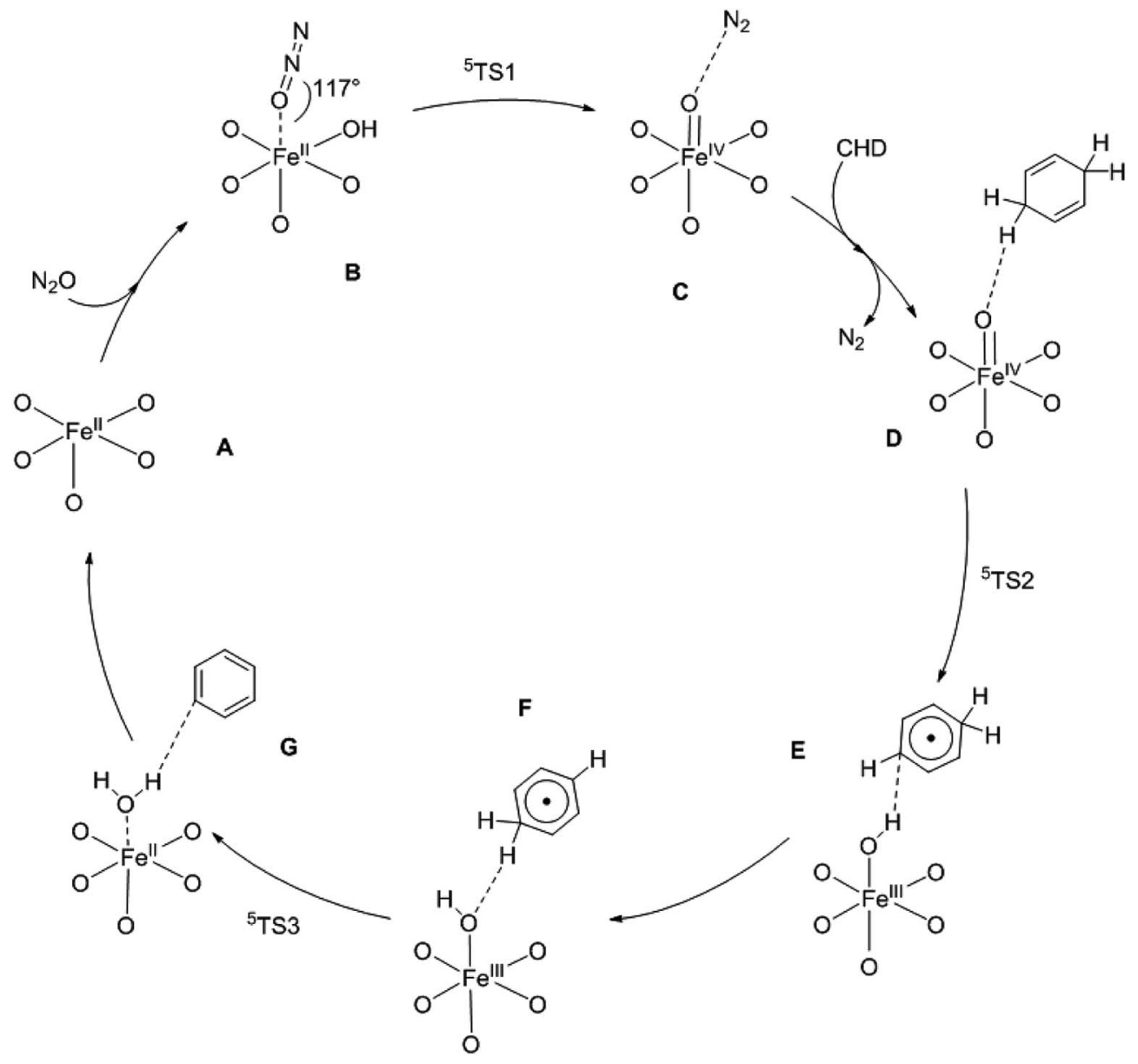

Scheme 1 The proposed mechanism for the oxidation of CHD to benzene with the catalysis of Fe/(Mg)-MOF-74. 
$\mathrm{N}_{2} \mathrm{O}$ adding on $\mathrm{Fe} /(\mathrm{Mg})-\mathrm{MOF}-74$ via TS1; (2) the first hydrogen abstraction of CHD by the Fe(Iv)-O intermediate via TS2; (3) the second hydrogen abstraction of $\mathrm{CHD}$ radical by $\mathrm{Fe}(\mathrm{III})-\mathrm{OH}$ intermediate to form benzene through TS3. Note that the above reactions in three processes on triplet and quintet potential energy surfaces (PESs) are plotted in Fig. 2, respectively.

It is found that the relative enthalpies of all species that react on the quintet state surface are generally lower than those of on triplet one. Note that although the barrier of ${ }^{3} \mathbf{T S 1}$ on the triplet surface is just $3.4 \mathrm{kcal} \mathrm{mol}^{-1}$, which is $16.0 \mathrm{kcal} \mathrm{mol}^{-1}$ lower than that of $19.4 \mathrm{kcal} \mathrm{mol}^{-1}$ of ${ }^{5} \mathbf{T S} 1$, which indicates that the triplet state is sometimes lower in energy compared with the quintet to bring about two-state reactivity of a hydroxylation reaction. This is consistent with recent computational work on the hydroxylation of methane using Fe(Iv)oxo in MOF-74. ${ }^{25}$ However, in this case, the adsorption enthalpy from $\mathbf{A}$ (the bare cluster) to $\mathbf{B}$ (the $\mathrm{N}_{2} \mathrm{O}$ bound to $\mathrm{Fe}$ of $\mathbf{A}$ ) is less than that of the quintet pathway $\left(2.2 \mathrm{kcal} \mathrm{mol}^{-1}\right.$ vs. $8.5 \mathrm{kcal} \mathrm{mol}^{-1}$ ), and the relative energy of the reactant is generally higher than that of the quintet surface at least $37.5 \mathrm{kcal} \mathrm{mol}^{-1}$. Note that the activation barrier ${ }^{5}$ TS2 and ${ }^{5}$ TS3 on quintet surface are just 3.5 and

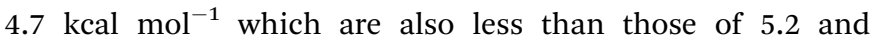
7.9 kcal mol ${ }^{-1}$ on triplet, respectively. So, the reaction will dominantly proceed on quintet PES and it is important to analyze the relevant structures of the hydrogen abstraction process between Fe/(Mg)-MOF-74 and CHD on quintet PES.

The important structures for the catalytic cycle reaction on quintet PES is shown in Fig. 3. From Scheme 1 and Fig. 3, it is found that the $\mathrm{Fe}-\mathrm{O}-\mathrm{N}$ angle is $117^{\circ}$ with $\mathrm{Fe}-\mathrm{O}$ bond at $2.48 \AA$ for the structure $\mathbf{B}$ which is in agreement with powder neutron diffraction data. ${ }^{22}$ The three steps including three transitionstate structures in the catalytic cycle are discussed in sequence as follows: (1) formation of a $\mathrm{Fe}(\mathrm{Iv})-\mathrm{O}$ intermediate via ${ }^{5}$ TS1: the first transition state about the cleavage of $\mathrm{N}-\mathrm{O}$ bond of $\mathrm{N}_{2} \mathrm{O}$ to form the $\mathrm{Fe}(\mathrm{Iv})-\mathrm{O}(\mathbf{A}-\mathbf{O})$ species is the rate-determining step with activation enthalpy of $19.4 \mathrm{kcal} \mathrm{mol}^{-1}$. The $\mathrm{Fe}-\mathrm{O}$ bond distance is shortened from $2.48 \AA$ in B to $1.87 \AA$ in ${ }^{5}$ TS1, while the $\mathrm{C}-\mathrm{H}$ bond distance is elongated from 1.20 to $1.49 \AA$. Then the $\mathbf{C}$ species is formed corresponding to an octahedron with $\mathrm{Fe}(\mathrm{Iv})-\mathrm{O}$ and $\mathrm{N}_{2}$. Note that the process from $\mathbf{B}$ to $\mathbf{C}$ is highly exothermic $\left(\Delta H=-15.6 \mathrm{kcal} \mathrm{mol}^{-1}\right)$; (2) the first hydrogen abstraction of CHD by $\mathrm{Fe}(\mathrm{Iv})-\mathrm{O}$ intermediate via ${ }^{5}$ TS2: when $\mathrm{N}_{2}$ gets away from $\mathbf{C}$ the CHD is bound to $\mathrm{Fe}(\mathrm{Iv})-\mathrm{O}$ to form $\mathbf{D}$ species. And the first hydrogen abstraction is accomplished via ${ }^{5}$ TS2 from $\mathbf{D}$ to form the $\mathrm{Fe}(\mathrm{III})-\mathrm{OH}$ with a nearby CHD radical (E). The activation enthalpy of ${ }^{5} \mathbf{T S} 2$ is $3.5 \mathrm{kcal} \mathrm{mol}^{-1}$, which is less than $13.9 \mathrm{kcal} \mathrm{mol}^{-1}$ reported by Xiao et $a .^{48}$ for oxidation of ethane. The reason may be that the bond dissociation energy (BDE) of CHD is less than that of ethane $\left(75.1 \mathrm{kcal} \mathrm{mol}^{-1} v s\right.$. $99.8 \mathrm{kcal} \mathrm{mol}^{-1}$ as listed in Table 3). Note that the Fe-O bond distance is elongated from 1.62 to $1.71 \AA$ from $\mathbf{D}$ to ${ }^{5} \mathbf{T S} 2$, while the $\mathrm{C}-\mathrm{H}$ bond is elongated from 1.10 to $1.23 \AA$; (3) the second hydrogen abstraction of $\mathrm{CHD}$ radical by $\mathrm{Fe}(\mathrm{III})-\mathrm{OH}$ intermediate to form benzene via ${ }^{5}$ TS3: the E species undergoes conformational change to form $\mathbf{F}$ species that is related to the second hydrogen bound to $\mathrm{Fe}(\mathrm{III})-\mathrm{OH}$ and the $\mathrm{Fe}(\mathrm{III})-\mathrm{OH}$ abstracts the second hydrogen of CHD radical to benzene (G) via ${ }^{\mathbf{5}} \mathbf{T S 3}$. Note that the $\mathrm{Fe}-\mathrm{O}$ bond distance is elongated from 1.85 to $1.93 \AA$ from $\mathbf{F}$ to ${ }^{5} \mathbf{T S} 3$, while the $\mathrm{C}-\mathrm{H}$ bond distance of $\mathrm{CHD}$ radical is elongated from 1.11 to $1.19 \AA$, indicating that the second hydrogen of CHD radical is close to $\mathrm{O}$ of $\mathrm{Fe}(\mathrm{III})-\mathrm{OH}$ while the $\mathrm{O}$ is away from Fe center. This makes the $\mathrm{H}_{2} \mathrm{O}$ easily separated from $\mathrm{Fe}(\mathrm{II})$ and the catalyst recyclable. At last, the reaction ends up with the products benzene, $\mathrm{N}_{2}$ and $\mathrm{H}_{2} \mathrm{O}$, which are in agreement with experiment. ${ }^{22}$

\subsection{The electronic structure analysis of species on quintet PES for oxidation of CHD}

In order to deeply understand the catalysis reaction mechanism, we also analyzed the electronic structures of quintet

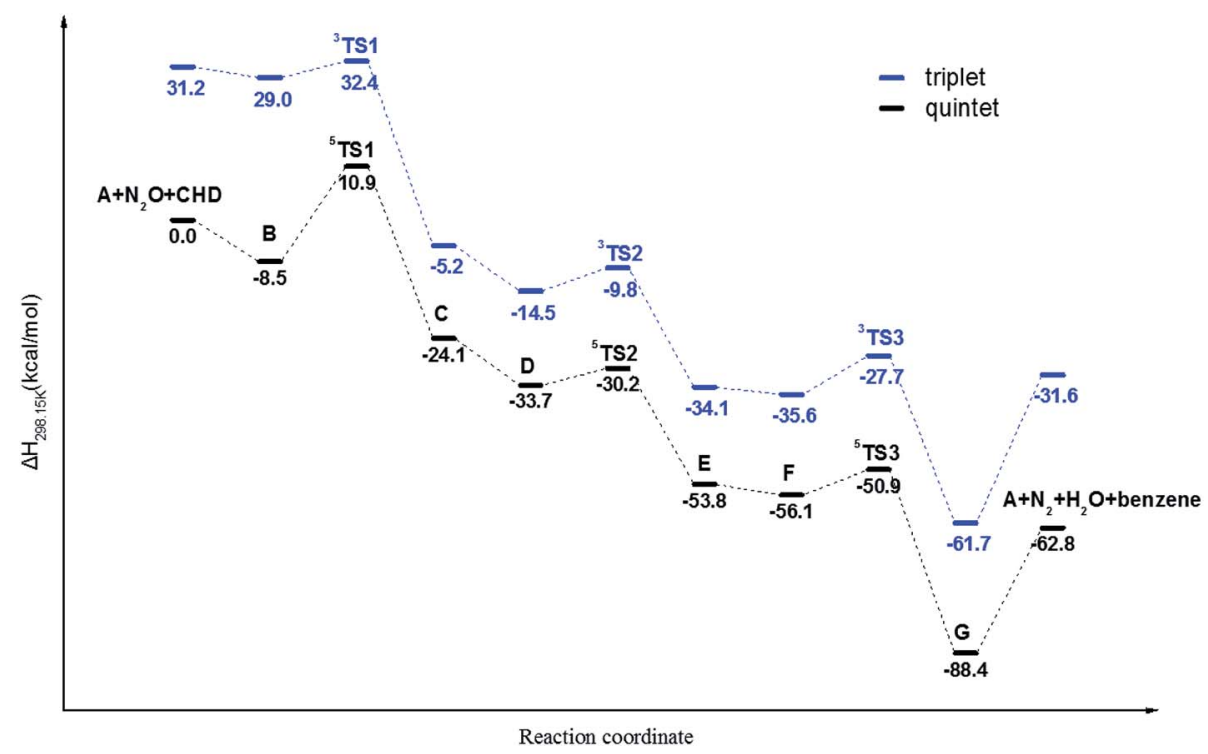

Fig. 2 The plotted enthalpy profiles of the catalytic oxidation of CHD by Fe/(Mg)-MOF-74 on triplet and quintet surfaces. 


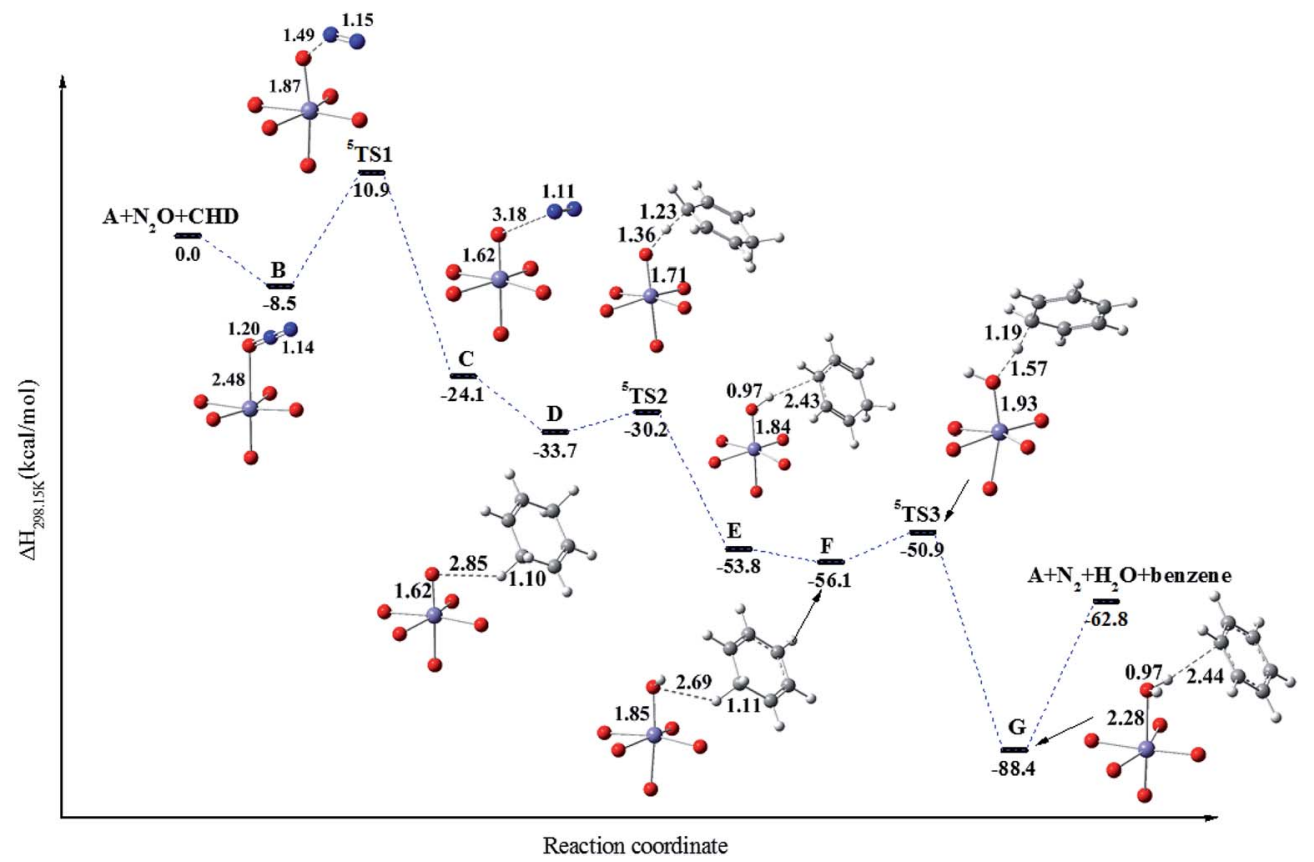

Fig. 3 The selected important information of the most favorable PES (quintet surface) for oxidation of CHD.

species. In Table 1, we listed the population, Wiberg bond index for the stationary points and TSs along the reaction path on quintet for the Fe center and oxygen atoms around. It is found that the spin density on the Fe center for all species lies between 2.90 and 3.90, and the unpaired electron on all species is significantly located the metal center (Fig. S1 $\dagger$ ), indicating that the Fe center is high-spin states. The NPA charge on the Fe center of bare cluster $\mathbf{A}$ and $\mathbf{B}$ are 1.09 and 1.03e, respectively, suggesting that the adsorption of $\mathrm{N}_{2} \mathrm{O}$ is followed by the negative charge transfer from the rest atoms of the complex to Fe. Note that the average NPA charge on the five oxygen atoms $\left(\mathrm{O}_{1-}\right.$ $\mathrm{O}_{5}$ ) around the Fe remains almost unchanged during hydrogen abstraction catalytic cycle, indicating no influence of the oxygen atoms bound to the Fe center. Similarly, the average bond distances of $\mathrm{Fe}-\mathrm{O}_{n}(n=1-5)$ show almost no change along the reaction pathway. After crossing over ${ }^{5} \mathbf{T S 1}$, the oxidation state of Fe center changes from II to IV. Meanwhile, the spin density on $\mathrm{Fe}$ atom is reduced from 3.65 (B) to 2.90 (C). This is also accompanied by the increase in spin density on $\mathrm{O}_{6}$ from 0.01 to 0.66 . The calculated bond distance and Wiberg bond index of $\mathrm{Fe}-\mathrm{O}_{6}$ are $1.62 \AA$ and 1.42 , respectively, indicating a double bond, which is in line with EXAFS and X-ray on Fe(Iv)-O length in heme ${ }^{49}$ and non-heme enzymes (1.64-1.68 $)^{50}{ }^{50}$

To gain more electronic structure information about hydrogen abstraction reaction, we also calculated the electron localized function (ELF) ${ }^{46,51}$ and orbital interaction. We mainly focus on the first hydrogen abstraction step, which possesses the features of significant interest. ${ }^{52}$ In Fig. 4 , the color-scale

Table 1 The calculated NPA charges (in atomic units), spin densities (in atomic units) for various species of the oxidation reaction of CHD catalyzed by Fe(Mg)-MOF-74

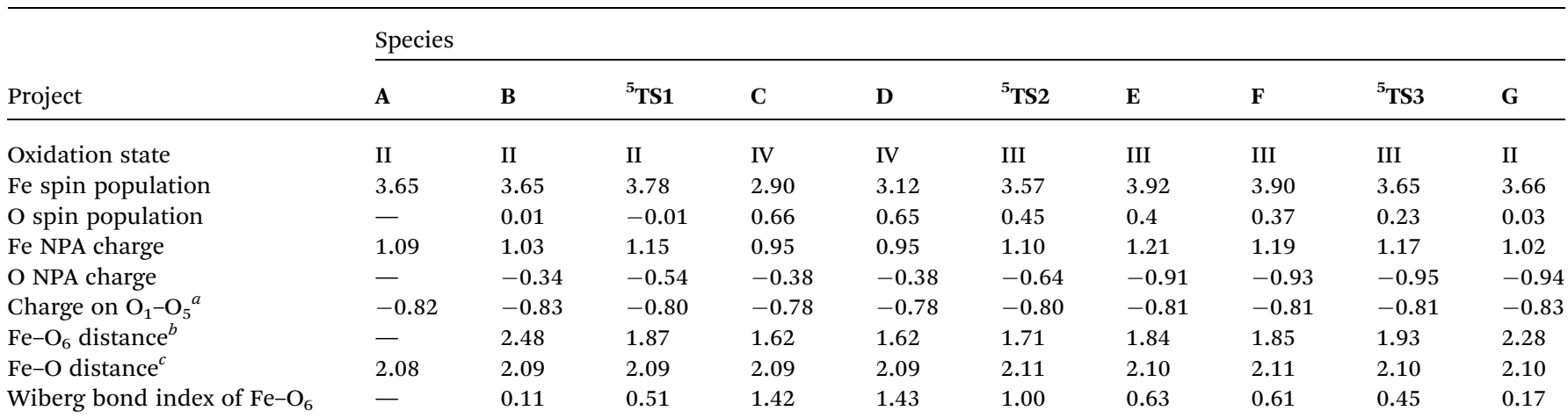

${ }^{a}$ Average charge on the five MOF oxygen atoms in the first coordination shell of Fe. ${ }^{b} \mathrm{O}_{6}$ is the oxygen atom transferred from $\mathrm{N}_{2} \mathrm{O}$ to the Fe center.

${ }^{c}$ Average $\mathrm{Fe}-\mathrm{O}$ distance for the five oxygen atoms $\left(\mathrm{O}_{1}-\mathrm{O}_{5}\right)$ in the first coordination shell of Fe. 


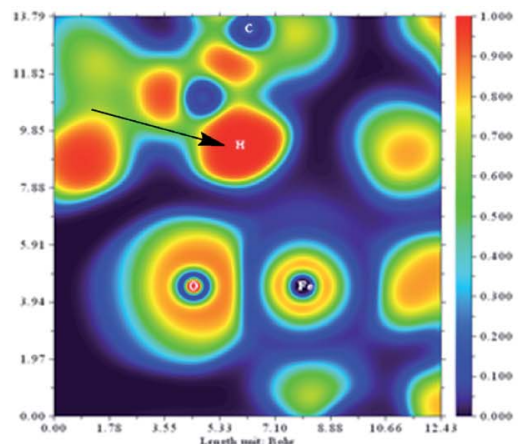

B

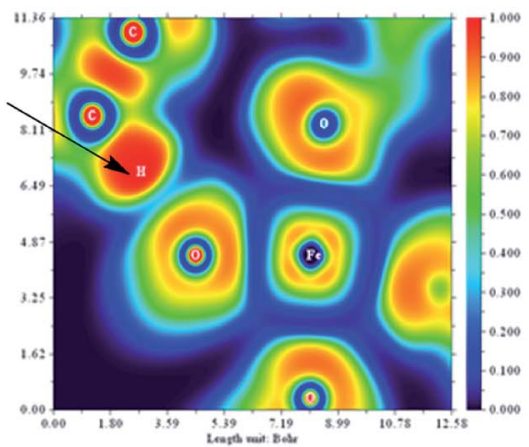

${ }^{5}$ TS2

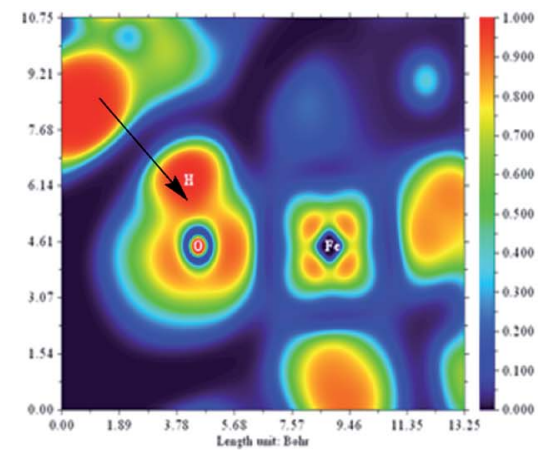

C

Fig. 4 Color-scale plot of the electron localization function (ELF) of species ${ }^{5} \mathrm{TS} 2$, B and C for the first hydrogen abstraction of CHD catalyzed by $\mathrm{Fe} /(\mathrm{Mg})-\mathrm{MOF}-74$.

plot of the electron localization function (ELF) of structure ${ }^{5}$ TS2, $\mathbf{B}$ and $\mathbf{C}$ is shown to describe the first hydrogen abstraction of $\mathrm{CHD}$ by $\mathrm{Fe} /(\mathrm{Mg})-\mathrm{MOF}-74$. ELF is a three-dimensional real space function with a numerical range between 0.0 and 1.0. In short, the areas surrounded by the ELF isosurface is of large ELF values, where electrons are more localized and are thus not easy to get out of it. On the contrary, the weak electron localization area is with small ELF value, indicating that the electrons placed there can be easily delved into other areas. Note that the deep blue area with the small ELF value between $\mathrm{O}$ and $\mathrm{H}$ atoms indicates the electron localization is weak in $\mathbf{B}$. As the reaction goes on, the $\mathrm{H}$ atom gets closer to the $\mathrm{O}$ atom, the ELF value slowly increases between $\mathrm{O}$ and $\mathrm{H}$ in ${ }^{5}$ TS2. Finally, when $\mathrm{H}$ atom transfers to $\mathrm{O}$ of $\mathrm{Fe}(\mathrm{rv})-\mathrm{O}$ nearby, the relatively smooth yellow area of the $\mathrm{O}-\mathrm{H}$ is formed, where the electrons are more localized between $\mathrm{H}$ and $\mathrm{O}$ atom in $\mathrm{C}$ species.

Since we cannot clarify the steric difference of the two transition states for oxidation of CHD, the reason for lower enthalpy of ${ }^{5} \mathbf{T S} 2$ compared with ${ }^{3} \mathbf{T S} 2$ requires an explanation. In Scheme 2, it is shown that on both triplet and quintet PESs, the d-area of $\mathrm{Fe}(\mathrm{Iv})-\mathrm{O}$ gets an electron during the hydrogen abstraction step and the $\sigma_{\mathrm{CH}}$ bond orbital of

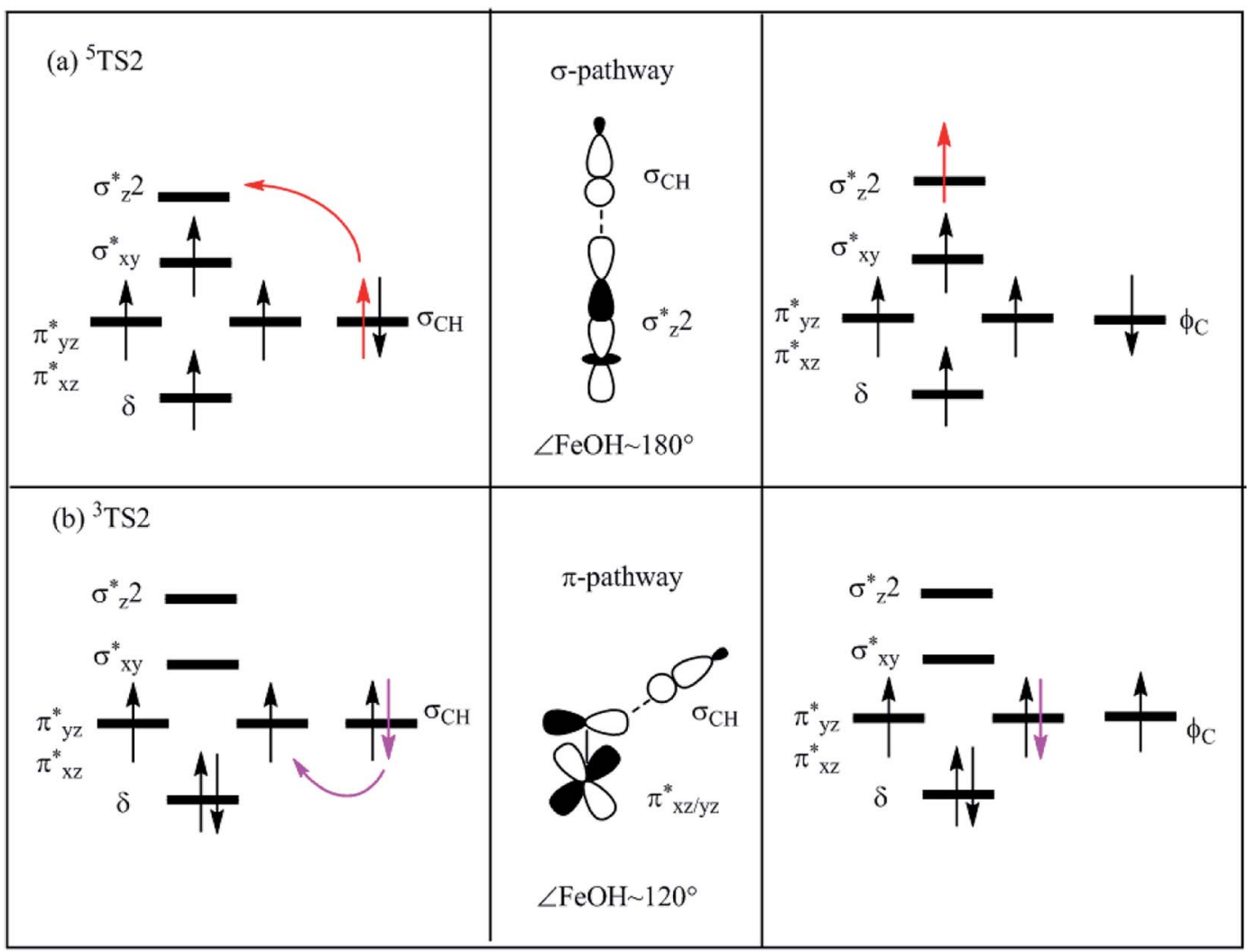

Scheme 2 Electron shifts diagrams during the first step of hydrogen abstraction on (a) quintet; and (b) triplet. 
the CHD is converted to a singly occupied orbital of the CHD $\phi_{\mathrm{C}}$. In Fig. S2(a)-(d), $\dagger$ from the plotted spin natural orbitals, natural orbitals and their occupations of ${ }^{5} \mathbf{A}-\mathbf{O},{ }^{3} \mathbf{A}-\mathbf{O},{ }^{5} \mathbf{T S 2}$ and ${ }^{3} \mathbf{T S} 2$, respectively, it is found that in ${ }^{5} \mathbf{T S} 2$, there is a spin-down electron in an $\phi_{\mathrm{C}}$ orbital which is located on the CHD and five unpaired spin-up electrons in the d-area. Thus, as shown in Scheme 2(a), the d-area of ${ }^{5}$ TS2 gets an electron in the unoccupied $\sigma_{z^{2}}^{*}$ orbital, while the $\mathrm{C}-\mathrm{H}$ bond orbital is transferred to a singly occupied spin-down orbital of CHD, which can be called as $\sigma$-pathway. On the other hand, in ${ }^{3} \mathbf{T S} 2$, there is a singly occupied spin-up electron in the d-area and another one in the CHD, as shown in Scheme 2(b). The gained d electron is now in $\mathrm{d}_{y z}$ orbital which is the main component of the $\pi_{y z}^{*}$ orbital, which can be called as $\pi$ pathway. Note that the d-area of ${ }^{5}$ TS2 gets a spin-up electron in the $\sigma_{z^{2}}^{*}$ orbital and ${ }^{3}$ TS2 gets a spin-down in the $\pi_{y z}^{*}$ orbital, and we have known the orbital-selection principle for the spin dependent orientation selectivity, ${ }^{53-56}$ therefore, the TSs may adjust the direction and tend to maximize the overlap of the two orbitals participating in the electronic transition. In Scheme 2(a), it is shown that a spin-up electron is transferred to the $\sigma_{z^{2}}^{*}$ orbital on quintet, and the favorable geometry of ${ }^{5}$ TS2 is the $\sigma_{\mathrm{CH}}-\sigma_{z^{2}}^{*}$ overlap. As can be seen from the overlap sketch map in Scheme 2(a), a vertical orientation of ${ }^{5}$ TS2 will maximize this overlap and suggest the preferred pathway of the transition state. By comparison with quintet, a spin-down electron of $\mathrm{C}-\mathrm{H}$ on triplet PES is transferred to one of the $\pi_{x z / y z}^{*}$ orbitals of Fe-O, and thus, the overlap sketch map shows that the preferred structure of ${ }^{3}$ TS2 should involve a sideway attack due to the large steric effect and the unavoidably increased Pauli repulsion, resulting in the attack angle to about $120^{\circ}$ and less overlap than the quintet one (Scheme 2(b)). It makes a rationalization that the activation enthalpy of ${ }^{5}$ TS2 is $3.5 \mathrm{kcal} \mathrm{mol}{ }^{-1}$ which is less than that of ${ }^{3}$ TS2 with $4.7 \mathrm{kcal} \mathrm{mol}^{-1}$ as shown in Fig. 2 .

\subsection{The rebound mechanism for the oxidation of cyclohexane (CHA)}

Xiao et al. ${ }^{22,23}$ have also reported that expanded Fe-MOF-74 analogues can oxidize CHA to cyclohexanol experimentally but the byproduct cyclohexanone will be produced. However, the Mg-diluted Fe-MOF-74, i.e., Fe/(Mg)-MOF-74 can hydroxylate alkanes to avoid overoxidation. Taking advantage of this, we considered that $\mathrm{Fe} /(\mathrm{Mg})-\mathrm{MOF}-74$ may hydroxylate $\mathrm{CHA}$ to avoid overoxidation. Note that the mechanism of CHA hydroxylation to cyclohexanol catalyzed by $\mathrm{Fe} /(\mathrm{Mg})-\mathrm{MOF}-74$ has not been reported either experimentally or theoretically.

In Fig. 5 , the favorable quintet PES and important structures for the CHA hydroxylation reaction using enthalpy change are plotted. The calculated $\Delta H$ and $\Delta G$ for various species are collected in Table S2. $\dagger$ Starting from the $\mathbf{H}$ species corresponding to the bound of CHA with $\mathrm{Fe}(\mathrm{Iv})-\mathrm{O}$, crossing the activation enthalpy $8.1 \mathrm{kcal} \mathrm{mol}^{-1}$ of TS4, which is less than that of $13.9 \mathrm{kcal} \mathrm{mol}^{-1}$ reported by Xiao et al. for oxidation of ethane, ${ }^{48}$ the species I will be formed corresponding to the broken of $\mathrm{C}-\mathrm{H}$ bond in $\mathrm{CHA}$ with exothermicity by $5.2 \mathrm{kcal} \mathrm{mol}^{-1}$. Note that the $\mathrm{Fe}-\mathrm{O}$ bond distance is elongated from 1.62 to $1.72 \AA$ from $\mathbf{H}$ to ${ }^{5} \mathbf{T S} 4$, while the $\mathrm{C}-\mathrm{H}$ bond is elongated from 1.10 to $1.32 \AA$ at the same time. The next step corresponds to the reaction of the $\mathrm{Fe}(\mathrm{III})-\mathrm{OH}$ species with the CHA radical to cyclohexanol via ${ }^{5}$ TS5. Note that the ${ }^{5}$ TS5 is formed after rotating a hydrogen atom of the hydroxo group along the $\mathrm{Fe}(\mathrm{III})-\mathrm{O}$ axis in intermediate $\mathbf{I}$ and the CHA radical

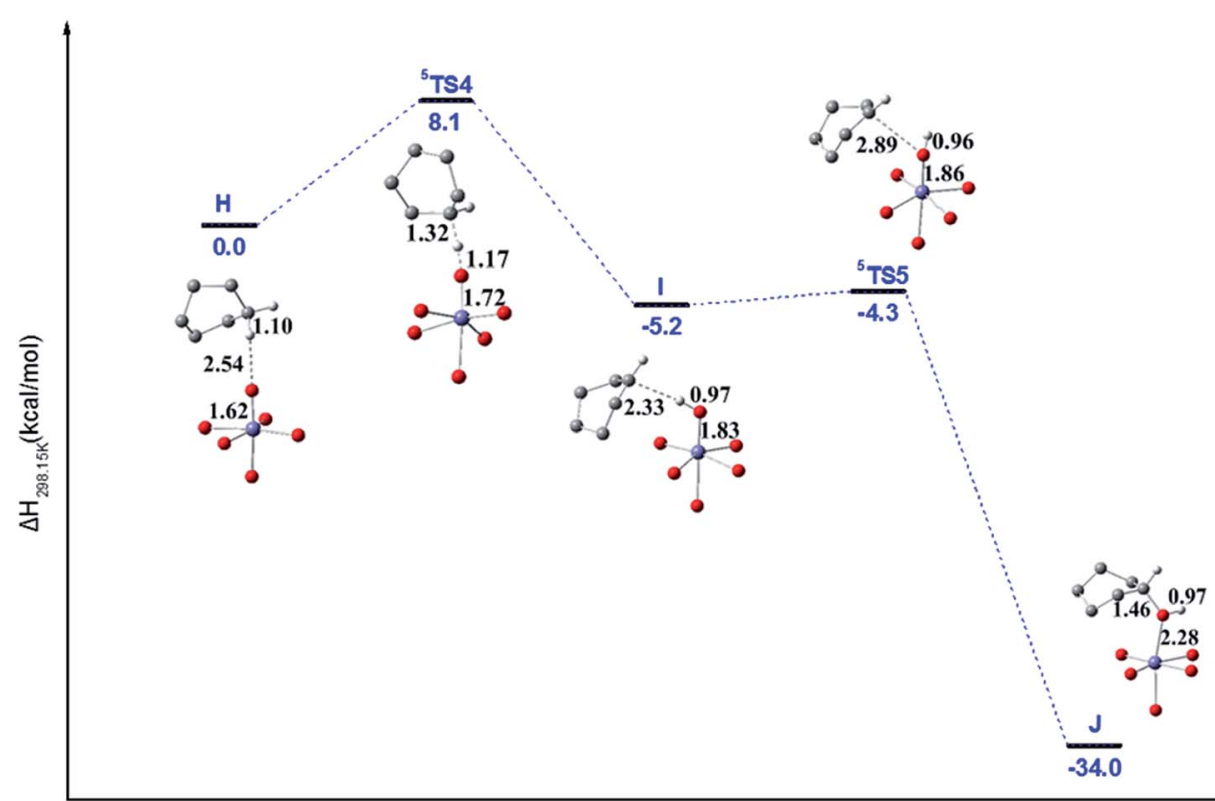

Reaction coordinate

Fig. 5 The selected important information of the most favorable PES (quintet surface) of cyclohexane hydroxylation to cyclohexanol with a rebound mechanism. Note that partial hydrogen atoms of cyclohexane are omitted for concision. 
moves closer to the oxyl on Fe(III) center. Note that from I to ${ }^{5}$ TS5, the Fe-O bond is elongated from 1.83 to $1.86 \AA$, with the activation enthalpy just $0.9 \mathrm{kcal} \mathrm{mol}^{-1}$. Finally, the $\mathrm{CHA}$ radical abstracted the hydroxyl group to form cyclohexanol (J).

The above reaction mechanism can be called as rebound mechanism since a radical produced by hydrogen abstraction rebound to oxygen atom of hydroxyl group to form alcohol. Note that the activation enthalpy of $8.1 \mathrm{kcal} \mathrm{mol}^{-1}$ for oxidation of CHA is larger than that of $3.5 \mathrm{kcal} \mathrm{mol}^{-1}$ of for hydrogen abstraction step in CHD. And different from the oxidation of CHD to benzene via two step hydrogen abstraction, the oxidation of CHA to cyclohexanol corresponds to a rebound mechanism.

\subsection{The linear relationships between $\mathrm{C}-\mathrm{H}$ bond activation enthalpies and descriptors of different hydrocarbons with the catalysis of $\mathrm{M} /(\mathrm{Mg})-\mathrm{MOF}-74(\mathrm{M}=\mathrm{Cu}, \mathrm{Ni}, \mathrm{Fe}$, and $\mathrm{Co})$}

It is important to evaluate the relationship between the $\mathrm{C}-\mathrm{H}$ bond activation enthalpies and descriptors like NPA charge of oxyl atom, $\mathrm{C}-\mathrm{H}$ bond length of TSs and bond dissociation energy (BDE) of $\mathrm{C}-\mathrm{H}$ bonds for methane, ethane, propane and CHD with $\mathrm{M} /(\mathrm{Mg})-\mathrm{MOF}-74(\mathrm{M}=\mathrm{Cu}, \mathrm{Ni}, \mathrm{Fe}$, and $\mathrm{Co})$, respectively. Generally, the chemical reactions may occur where the charge is concentrated, so the ability of $\mathrm{M}-\mathrm{O}$ clusters for methane activation is known to be actually sensitive to the charge density on $\mathrm{O}$ of $\mathrm{M}-\mathrm{O}$ clusters, ${ }^{57,58}$ and the NPA charge of $\mathrm{O}$ may serve as a predictive descriptor.

Take the hydrogen abstraction of methane as an example, it is shown that the activation enthalpies and NPA charges in reactions catalyzed by $\mathrm{M} /(\mathrm{Mg})-\mathrm{MOF}-74(\mathrm{M}=\mathrm{Cu}, \mathrm{Ni}, \mathrm{Fe}$, and $\mathrm{Co})$ are $8.8,11.7,15.3$, and $19.4 \mathrm{kcal} \mathrm{mol}^{-1}$ as well as -0.682 , $-0.687,-0.712$, and $-0.714 e$, respectively, as listed in Table 2 . In Fig. 6(a), it is shown that there exists the linear relationship between the activation enthalpies and the NPA charges of the reacting oxyl atom, i.e., the less of absolute value of NPA charge of oxyl atom, the lower of the activation enthalpy $\left(R^{2}=0.810\right)$.

In the following, we turn to analyze the $\mathrm{C}-\mathrm{H}$ bond lengths of transition state structures. It is shown that the $\mathrm{C}-\mathrm{H}$ bond lengths of methane in TSs on quintet PES catalyzed by $\mathrm{M} / \mathrm{Mg}$ MOF-74 (M = Cu, Ni, Fe, and Co) are 1.299, 1.307, 1.351, and $1.442 \AA$, respectively, as collected in Table 2 . Note that the activation enthalpies in reactions catalyzed by $\mathrm{M} / \mathrm{Mg}-\mathrm{MOF}-74$ $(\mathrm{M}=\mathrm{Cu}, \mathrm{Ni}, \mathrm{Fe}$, and $\mathrm{Co})$ are $8.8,11.7,15.3$, and $19.4 \mathrm{kcal} \mathrm{mol}^{-1}$, respectively. And there is a linear correlation

Table 2 The calculated activation enthalpy, $\mathrm{C}-\mathrm{H}$ bond length of TS and NPA charges of oxyl for the oxidation reaction of methane catalyzed by $\mathrm{M} /(\mathrm{Mg})-\mathrm{MOF}-74(\mathrm{M}=\mathrm{Cu}, \mathrm{Ni}, \mathrm{Fe}$, and $\mathrm{Co})$

\begin{tabular}{lllll}
\hline & \multicolumn{4}{l}{ Metal center } \\
\cline { 2 - 5 } Project & $\mathrm{Cu}$ & $\mathrm{Ni}$ & $\mathrm{Fe}$ & $\mathrm{Co}$ \\
\hline Activation enthalpy $\left(\mathrm{kcal} \mathrm{mol}^{-1}\right)$ & 8.8 & 11.7 & 15.3 & 19.4 \\
C-H bond length of TS $(\AA)$ & 1.299 & 1.307 & 1.351 & 1.442 \\
NPA charge of oxyl $(e)$ & -0.682 & -0.687 & -0.712 & -0.714
\end{tabular}

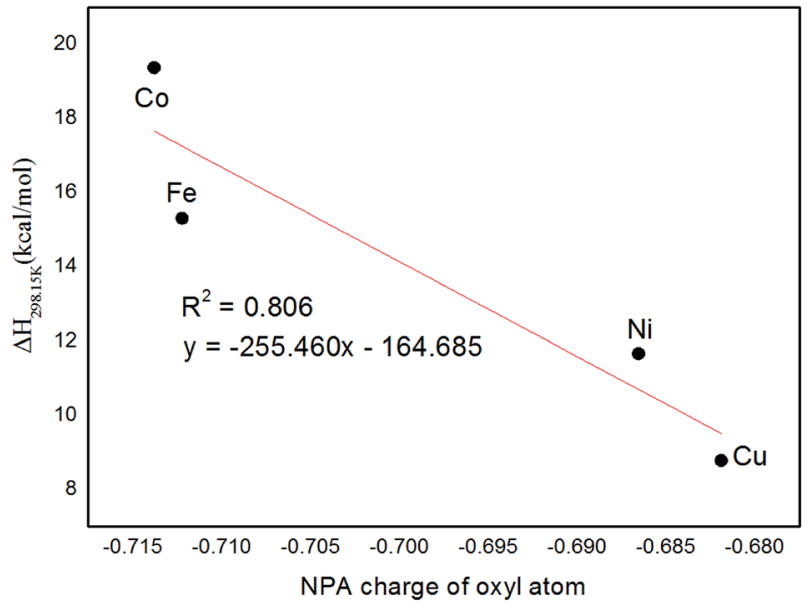

(a)

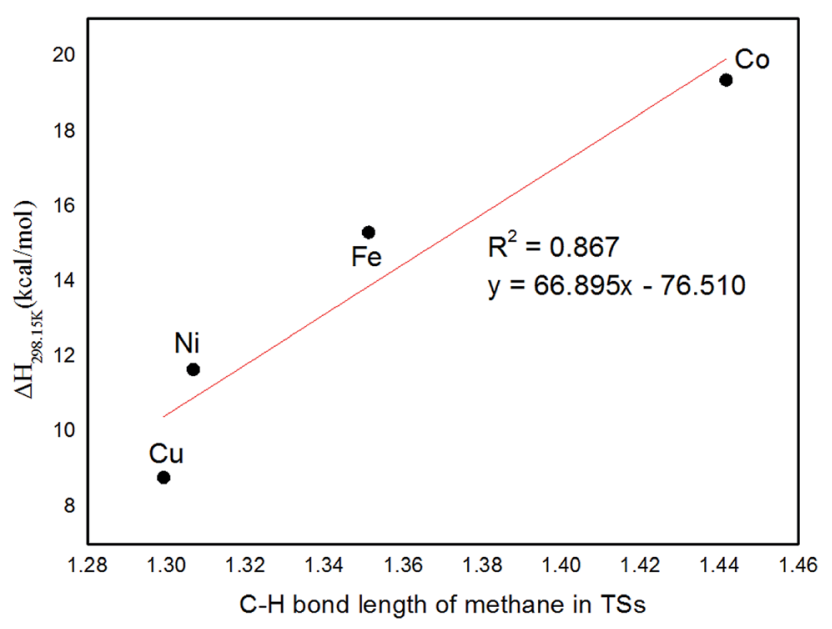

(b)

Fig. 6 Plots of activation enthalpy $(\Delta H)$ of methane versus (a) NPA charge of oxyl atom; (b) $\mathrm{C}-\mathrm{H}$ bond length in TSs for M/(Mg)-MOF-74 $(\mathrm{M}=\mathrm{Cu}, \mathrm{Ni}, \mathrm{Fe}$, and $\mathrm{Co})$. Note that regression line is in red.

between $\mathrm{C}-\mathrm{H}$ bond lengths of TSs and activation enthalpies of the reaction of different $\mathrm{M}-\mathrm{O}$ clusters as plotted in Fig. 6(b) $\left(R^{2}\right.$ $=0.870$ ). This means shorter $\mathrm{C}-\mathrm{H}$ bonds in TSs is associated with lower activation enthalpy. Furthermore, the activation enthalpies and $\mathrm{C}-\mathrm{H}$ bond length of TSs for methane, ethane, propane and CHD catalyzed by Fe/(Mg)-MOF-74 are 15.3, 11.4, 10.3 , and $3.5 \mathrm{kcal} \mathrm{mol}^{-1}$, as well as $1.351,1.310,1.265$, and 1.226

Table 3 The calculated activation enthalpy, $\mathrm{C}-\mathrm{H}$ bond length of TS and bond dissociation energy (BDE) for the oxidation reaction of methane, ethane, propane, CHD catalyzed by Fe/(Mg)-MOF-74

\begin{tabular}{|c|c|c|c|c|}
\hline \multirow[b]{2}{*}{ Project } & \multicolumn{4}{|c|}{ Hydrocarbon } \\
\hline & Methane & Ethane & Propane & CHD \\
\hline Activation enthalpy $\left(\mathrm{kcal} \mathrm{mol}^{-1}\right)$ & 15.3 & 11.4 & 10.3 & 3.5 \\
\hline $\mathrm{C}-\mathrm{H}$ bond length of TS $(\AA)$ & 1.351 & 1.310 & 1.265 & 1.226 \\
\hline $\mathrm{C}-\mathrm{H}$ bond (BDE) $\left(\mathrm{kcal} \mathrm{mol}^{-1}\right)$ & 103.9 & 99.8 & 96.9 & 75.1 \\
\hline
\end{tabular}


$\AA$, respectively, as listed in Table 3 . Obviously, both the activation enthalpies and $\mathrm{C}-\mathrm{H}$ bond lengths decrease as the number of carbon atom increases. It also has a linear correlation between $\mathrm{C}-\mathrm{H}$ bond lengths of TSs and activation enthalpies of the reaction of different hydrocarbon as plotted in Fig. 7(a) $\left(R^{2}\right.$ $=0.863)$.

These results are clearly in agreement with the Hammond hypothesis, ${ }^{59}$ i.e., a more reactive oxyl (less activation enthalpies) should have a transition state (TS) structure closer to reactants. Note that it is clear that for the hydrogen abstraction reaction of methane with catalysis of $\mathrm{Cu} /(\mathrm{Mg})-\mathrm{MOF}$ 74, there exist the lowest activation enthalpy as plotted in Fig. 6. The reason may result from that $\mathrm{Cu} /(\mathrm{Mg})-\mathrm{MOF}-74$ has the largest NPA charge $(-0.682 e)$ and shortest $\mathrm{C}-\mathrm{H}$ bond length $(1.299 \AA)$ in TS compared with those of $\mathrm{M} /(\mathrm{Mg})-\mathrm{MOF}-74(\mathrm{M}=\mathrm{Ni}$, $\mathrm{Fe}$, and $\mathrm{Co})$. We hope the present theoretical result may stimulate the experimental synthesis of $\mathrm{Cu} /(\mathrm{Mg})-\mathrm{MOF}-74$ further.

In addition, inspired by the report on dissociation energy of molecular fragments $\left[-\mathrm{OH},-\mathrm{OCH}_{3}\right.$, and $\left.-\mathrm{O}(\mathrm{O}) \mathrm{CH}\right]$ on $\mathrm{Pt}(1,1,1)$

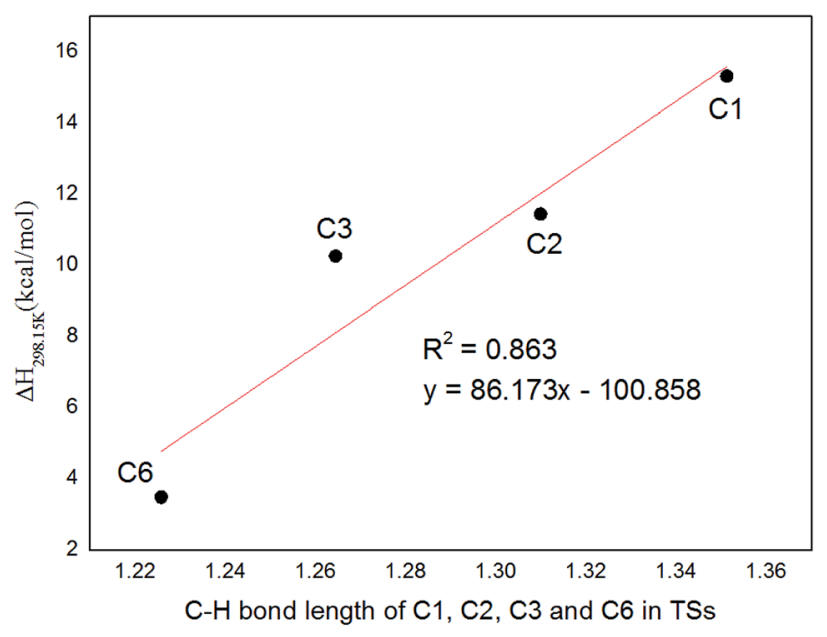

(a)

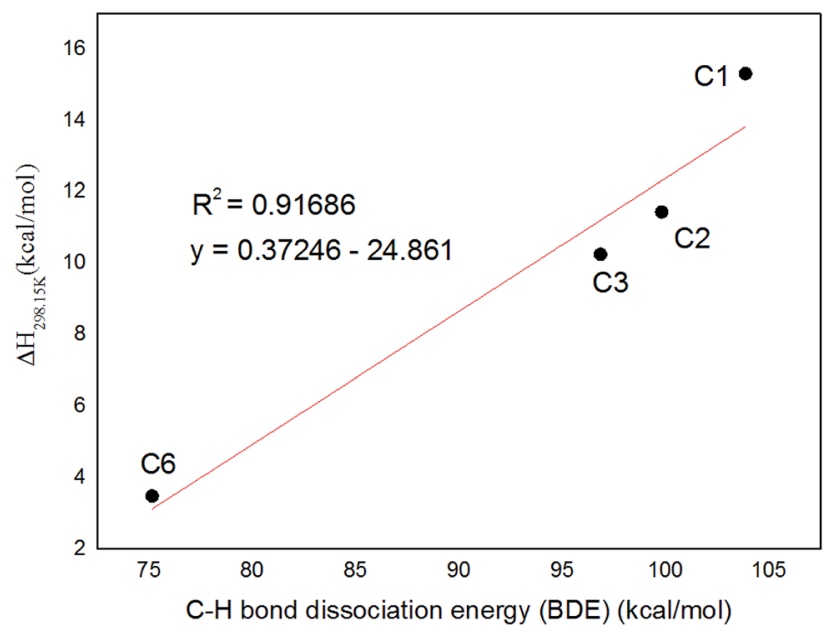

(b)

Fig. 7 Plots of activation enthalpy $(\Delta H)$ versus (a) $\mathrm{C}-\mathrm{H}$ bond length in TSs; and (b) $\mathrm{C}-\mathrm{H}$ bond dissociation energy (BDE) for $\mathrm{C} 1, \mathrm{C} 2, \mathrm{C} 3, \mathrm{C} 6$ species. Note that regression line is in red. surfaces by Eric M. Karp et al. ${ }^{\mathbf{6 0}}$ we expect different hydrocarbon catalyzed by $\mathrm{Fe} /(\mathrm{Mg})-\mathrm{MOF}-74$ to be related to the reactant's $\mathrm{C}-\mathrm{H}$ bond dissociation energy (BDE). From Table 3, we found that the activation enthalpies and $\mathrm{BDE}$ of $\mathrm{C}-\mathrm{H}$ bond for methane, ethane, propane and CHD (C1, C2, C3, and C6) are 15.3, 11.4, 10.3 , and $3.5 \mathrm{kcal} \mathrm{mol}^{-1}$ as well as 103.9, 99.8, 96.9, and $75.1 \mathrm{kcal} \mathrm{mol}^{-1}$, respectively. It is clear that the BDE of C6 is less than that of $\mathrm{C} 1, \mathrm{C} 2$ and $\mathrm{C} 3$, so $\mathrm{CHD}$ is the easiest one to be activated. From Fig. 7(b), it is shown that there exists linear correlation between the activation enthalpies and bond dissociation energies (BDEs) of $\mathrm{C}-\mathrm{H}$ bonds in methane, ethane, propane and CHD (C1, C2, C3, and C6) $\left(R^{2}=0.917\right)$. According to this, we can estimate activation enthalpy without needing to optimize the TS structures.

\section{Conclusions}

In this article, we mainly explored the reaction mechanisms of activation of $\mathrm{C}-\mathrm{H}$ bonds in $\mathrm{CHD}$ and $\mathrm{CHA}$ catalyzed by enzymelike $\mathrm{Fe} /(\mathrm{Mg})-\mathrm{MOF}-74$ based on the density functional theory at the M06-L-D3 level. It is found that in the presence of oxidant $\mathrm{N}_{2} \mathrm{O}$, the magnesium-diluted $\mathrm{MOF}$, i.e., $\mathrm{Fe} /(\mathrm{Mg})-\mathrm{MOF}-74$, can catalyze the activation of $\mathrm{C}-\mathrm{H}$ bond of $\mathrm{CHD}$ by hydrogen transfer to benzene. It is shown that the first transition state (TS1) on quintet PES corresponding to the cleavage of $\mathrm{N}-\mathrm{O}$ bond of $\mathrm{N}_{2} \mathrm{O}$ to the $\mathrm{Fe}(\mathrm{Iv})-\mathrm{O}$ species is the rate-determining step with activation enthalpy of $19.4 \mathrm{kcal} \mathrm{mol}^{-1}$ followed by two-step hydrogen abstraction processes with TS2 and TS3, respectively, with exothermicity of $62.8 \mathrm{kcal} \mathrm{mol}^{-1}$. The electronic structure calculations indicate that the reaction favors the " $\sigma$ pathway" via a linear attack between $\sigma_{\mathrm{CH}}$ orbital of CHD and $\sigma_{z^{2}}^{*}$ orbital of $\mathrm{Fe}(\mathrm{IV})-\mathrm{O}$ on quintet surface, rather than on triplet one. Different from the two-step hydrogen abstraction from CHD to benzene, the CHA can be oxidized to cyclohexanol with a rebound mechanism that involves $\mathrm{H}$ atom bonded to $\mathrm{O}$ atom of $\mathrm{Fe}-\mathrm{O}$ at first, and $\mathrm{CHA}$ radical moves closer to the $\mathrm{O}$ atom on $\mathrm{Fe}(\mathrm{III})$ center to form cyclohexanol.

In addition, for the catalysis by $\mathrm{M} /(\mathrm{Mg})-\mathrm{MOF}-74(\mathrm{M}=\mathrm{Cu}, \mathrm{Ni}$, $\mathrm{Fe}$, and $\mathrm{Co}$ ) of hydrogen abstraction of methane, it is found that there exists linear relationships between the activation enthalpies, $\mathrm{C}-\mathrm{H}$ bond lengths of hydrogen-abstraction transition states, and NPA charge of the reacting oxyl atoms, i.e., shorter $\mathrm{C}-\mathrm{H}$ bond and less absolute value of NPA charge of oxyl atom are associated with lower activation enthalpy. It should be noted that there is the lowest activation enthalpy for the hydrogen abstraction reaction of methane with the catalysis of $\mathrm{Cu} /(\mathrm{Mg})-\mathrm{MOF}-74$. With the catalysis of $\mathrm{Fe} /(\mathrm{Mg})-\mathrm{MOF}-74$, it is shown that the $\mathrm{C}-\mathrm{H}$ bond dissociation energies (BDEs) and the $\mathrm{C}-\mathrm{H}$ bond lengths in TSs of methane, ethane, propane, and CHD have a positive correlation versus their activation enthalpies, i.e., the lower BDE of hydrocarbon and shorter $\mathrm{C}-\mathrm{H}$ bond length of TS correspond to lower activation enthalpies. The above descriptors should be useful to predict the catalysis activity of enzyme-like MOF in activating $\mathrm{C}-\mathrm{H}$ bond. We hope the present theoretical modeling may give a guide toward the synthesis of metalloenzyme-like MOFs for the activation of $\mathrm{C}-\mathrm{H}$ bond. 


\section{Conflicts of interest}

There are no conflicts to declare.

\section{Acknowledgements}

The work was supported by the National Natural Science Foundation of China (No. 21373112, 21790371).

\section{References}

1 H. Arakawa, M. Aresta, J. N. Armor, M. A. Barteau, E. J. Beckman, A. T. Bell, J. E. Bercaw, C. Creutz, E. Dinjus, D. A. Dixon, K. Domen, D. L. DuBois, J. Eckert, E. Fujita, D. H. Gibson, W. A. Goddard, D. W. Goodman, J. Keller, G. J. Kubas, H. H. Kung, J. E. Lyons, L. E. Manzer, T. J. Marks, K. Morokuma, K. M. Nicholas, R. Periana, L. Que, J. Rostrup-Nielson, W. M. H. Sachtler, L. D. Schmidt, A. Sen, G. A. Somorjai, P. C. Stair, B. R. Stults and W. Tumas, Chem. Rev., 2001, 101, 953-996. 2 R. G. Bergman, Nature, 2007, 446, 391.

3 K. D. Karlin, Science, 1993, 261, 701.

4 C. E. Valdez, Q. A. Smith, M. R. Nechay and A. N. Alexandrova, Acc. Chem. Res., 2014, 47, 3110-3117.

5 F. Schwizer, Y. Okamoto, T. Heinisch, Y. Gu, M. M. Pellizzoni, V. Lebrun, R. Reuter, V. Köhler, J. C. Lewis and T. R. Ward, Chem. Rev., 2018, 118, 142-231. 6 W. Nam, Acc. Chem. Res., 2007, 40, 465.

7 J. Hohenberger, K. Ray and K. Meyer, Nat. Commun., 2012, 3, 720.

8 J. T. Groves, J. Inorg. Biochem., 2006, 100, 434-447.

9 K. Ray, F. F. Pfaff, B. Wang and W. Nam, J. Am. Chem. Soc., 2014, 136, 13942-13958.

10 S. Ye and F. Neese, Proc. Natl. Acad. Sci. U. S. A., 2011, 108, 1228.

11 O. Pestovsky, S. Stoian, E. L. Bominaar, X. Shan, E. Münck, L. Que and A. Bakac, Angew. Chem., Int. Ed., 2005, 44, 6871-6874.

12 L. Bernasconi, M. J. Louwerse and E. J. Baerends, Eur. J. Inorg. Chem., 2007, 2007, 3023-3033.

13 J. England, M. Martinho, E. R. Farquhar, J. R. Frisch, E. L. Bominaar, E. Münck and L. Que, Angew. Chem., 2009, 121, 3676-3680.

14 S. Kitagawa, R. Kitaura and S. Noro, Angew. Chem., Int. Ed. Engl., 2004, 43, 2334-2375.

15 H.-C. Zhou, J. R. Long and O. M. Yaghi, Chem. Rev., 2012, 112, 673-674.

16 Z. Y. Gu, J. Park, A. Raiff, Z. Wei and H. C. Zhou, ChemCatChem, 2013, 6, 67-75.

17 G. Ferey, Chem. Soc. Rev., 2008, 37, 191-214.

18 J. Lee, O. K. Farha, J. Roberts, K. A. Scheidt, S. T. Nguyen and J. T. Hupp, Chem. Soc. Rev., 2009, 38, 1450-1459.

19 M. Yoon, R. Srirambalaji and K. Kim, Chem. Rev., 2012, 112, 1196-1231.

20 T. Ikuno, J. Zheng, A. Vjunov, M. Sanchez-Sanchez, M. A. Ortuño, D. R. Pahls, J. L. Fulton, D. M. Camaioni, Z. Li, D. Ray, B. L. Mehdi, N. D. Browning, O. K. Farha,
J. T. Hupp, C. J. Cramer, L. Gagliardi and J. A. Lercher, J. Am. Chem. Soc., 2017, 139, 10294-10301.

21 S. Impeng, S. Siwaipram, S. Bureekaew and M. Probst, Phys. Chem. Chem. Phys., 2017, 19, 3782-3791.

22 D. J. Xiao, E. D. Bloch, J. A. Mason, W. L. Queen, M. R. Hudson, N. Planas, J. Borycz, A. L. Dzubak, P. Verma, K. Lee, F. Bonino, V. Crocella, J. Yano, S. Bordiga, D. G. Truhlar, L. Gagliardi, C. M. Brown and J. R. Long, Nat. Chem., 2014, 6, 590-595.

23 D. J. Xiao, J. Oktawiec, P. J. Milner and J. R. Long, J. Am. Chem. Soc., 2016, 138, 14371-14379.

24 W. Kohn, A. D. Becke and R. G. Parr, J. Phys. Chem., 1996, 100, 12974-12980.

25 F. Saiz and L. Bernasconi, Phys. Chem. Chem. Phys., 2019, 21, 4965.

26 S. Grimme, J. Comput. Chem., 2004, 25, 1463-1473.

27 S. Grimme, J. Comput. Chem., 2006, 27, 1787-1799.

28 S. Grimme, J. Antony, S. Ehrlich and H. Krieg, J. Chem. Phys., 2010, 132, 154104.

29 L. Valenzano, B. Civalleri, S. Chavan, G. T. Palomino, C. O. Areán and S. Bordiga, J. Phys. Chem. C, 2010, 114, 11185-11191.

30 C. R. A. Daniel, N. M. Rodrigues, N. B. da Costa and R. O. Freire, J. Phys. Chem. C, 2015, 119, 23398-23406.

31 R. Poloni, B. Smit and J. B. Neaton, J. Am. Chem. Soc., 2012, 134, 6714-6719.

32 K. Lee, J. D. Howe, L.-C. Lin, B. Smit and J. B. Neaton, Chem. Mater., 2015, 27, 668-678.

33 Y. Zhao and D. G. Truhlar, Theor. Chem. Acc., 2008, 120, 215241.

34 Y. Zhao and D. G. Truhlar, Acc. Chem. Res., 2008, 41, 157-167. 35 Y. Zhao and D. G. Truhlar, Chem. Phys. Lett., 2011, 502, 1-13. 36 Y. Zhao and D. G. Truhlar, J. Phys. Chem. C, 2008, 112, 68606868.

37 M. SwartAndré, A. R. Groenhof, A. W. Ehlers and K. Lammertsma, J. Phys. Chem. A, 2004, 108, 5479-5483.

38 D. Feller, J. Comput. Chem., 1996, 17, 1571-1586.

39 K. L. Schuchardt, B. T. Didier, T. Elsethagen, L. Sun, V. Gurumoorthi, J. Chase, J. Li and T. L. Windus, J. Chem. Inf. Model., 2007, 47, 1045-1052.

40 L. E. Roy, P. J. Hay and R. L. Martin, J. Chem. Theory Comput., 2008, 4, 1029-1031.

41 R. Ditchfield, W. J. Hehre and J. A. Pople, J. Chem. Phys., 1971, 54, 724-728.

42 F. Weigend and R. Ahlrichs, Phys. Chem. Chem. Phys., 2005, 7, 3297-3305.

43 M. J. Frisch, G. W. Trucks and H. B. Schlegel, Gaussian, Wallingford, CT, USA, 2016.

44 E. D. Glendening, A. E. Reed, J. E. Carpenter and F. Weinhold, NBO Program, Version 3.1.

45 A. E. Reed, R. B. Weinstock and F. Weinhold, J. Chem. Phys., 1985, 83, 735-746.

46 T. Lu and F.-W. Chen, Acta Phys.-Chim. Sin., 2011, 27, 27862792.

47 T. Lu and F. Chen, J. Comput. Chem., 2011, 33, 580-592. 
48 P. Verma, K. D. Vogiatzis, N. Planas, J. Borycz, D. J. Xiao, J. R. Long, L. Gagliardi and D. G. Truhlar, J. Am. Chem. Soc., 2015, 137, 5770-5781.

49 T. L. Poulos, Chem. Rev., 2014, 114, 3919-3962.

50 C. Krebs, D. Galonić Fujimori, C. T. Walsh and J. M. Bollinger, Acc. Chem. Res., 2007, 40, 484-492.

51 R. F. W. Bader, Atoms in Molecules: A Quantum Theory, Oxford University Press, Oxford, U.K., 1990.

52 L. Que, Acc. Chem. Res., 2007, 40, 493-500.

53 H. Hirao, D. Kumar, L. Que and S. Shaik, J. Am. Chem. Soc., 2006, 128, 8590-8606.

54 S. Shaik, H. Chen and D. Janardanan, Nat. Chem., 2010, 3, 19.
55 S. Shaik, H. Hirao and D. Kumar, Acc. Chem. Res., 2007, 40, 532-542.

56 H. Chen, W. Lai and S. Shaik, J. Phys. Chem. Lett., 2010, 1, 1533-1540.

57 N. Dietl, M. Schlangen and H. Schwarz, Angew. Chem., Int. Ed., 2012, 51, 5544-5555.

58 X.-L. Ding, X.-N. Wu, Y.-X. Zhao and S.-G. He, Acc. Chem. Res., 2012, 45, 382-390.

59 G. S. Hammond, J. Am. Chem. Soc., 1955, 77, 334-338.

60 E. M. Karp, T. L. Silbaugh and C. T. Campbell, J. Am. Chem. Soc., 2014, 136, 4137-4140. 